\title{
Analysis of basal serum TSH, FT3, and FT4 levels based on age, sampling time in women with infertility
}

Yuchao Zhang ${ }^{1}$, Wenbin Wu' ${ }^{1}$, Yanli Liu' ${ }^{1}$ Xingling Wang ${ }^{1}$, Yichun Guan ${ }^{\text {* }}$ and Liting Jia ${ }^{2}$

\begin{abstract}
Background: To analyze the characteristics of basal thyroid hormone levels in infertile women consulting for assisted reproductive technology (ART) treatment.

Methods: This was a retrospective study. Serum TSH, FT3 and FT4 levels of women seeking ART consultation were tested routinely. Analyses were performed based on age and sampling time. One-way ANOVA or Kruskal-Wallis rank sum test was used to compare the continuous data among the groups, and the chi-square test or Fisher's exact test was used to compare categorical data where appropriate.
\end{abstract}

Results: A total of 6426 women were initially included in the study. After exclusion criteria were applied, the remaining 4126 women were categorized into different groups. The prevalence of subclinical hypothyroidism significantly decreased with age and sampling time, from 21.09 to $11.91 \%$ and from 28.57 to $10.67 \%$, respectively $(P<0.001$, respectively). Mean serum TSH, FT3, and FT4 levels decreased significantly with age $(P=0.017,<0.001,<0.001$, respectively). In the context of sampling time, TSH levels from early in the morning were significantly higher $(P<0.001)$, while FT4 and FT3 levels were similar in different groups ( $P=0.258,0.300$, respectively).

Conclusions: The prevalence of subclinical hypothyroidism significantly decreased with increasing age and sampling time, as did the serum TSH levels. Even though, the establishment of reference interval of TSH level based on age or sampling time was not recommended. Full consideration of age and sampling time should be carefully taken before initiation of treatment.

Keywords: Thyroid stimulating hormones (TSH), Free triiodothyronine (FT3), Free serum thyroxine (FT4), Infertile factors, Female age, Sampling time

\section{Background}

Thyroid dysfunction is an important factor that adversely affects the outcome of pregnancy and ART, and affect $2-3 \%$ of pregnant women [1]. Thyroid hormones which are the most biomarkers for the diagnosis of thyroid function, are critical for substance metabolism, energy

\footnotetext{
*Correspondence: guanyichun3661@163.com

${ }^{1}$ Department of Reproductive Medicine, The Third Affiliated Hospita of Zhengzhou University, No. 7 Kangfuqian Street, Erqi, Zhengzhou, Henan, China

Full list of author information is available at the end of the article
}

production, early placental formation and neurological development. Treatment of thyroid dysfunction tremendously improves infertility treatment outcomes such as increased implantation rate, decreased miscarriage rate, and increased delivery rate. However, current opinions on whether universal screening for thyroid function should be performed before or during pregnancy are still controversial. We agree with the suggestion that recommendation of universal screening for women undergo infertility treatment should base on the prevalence of thyroid dysfunction in the population with infertility.

(c) The Author(s) 2021. Open Access This article is licensed under a Creative Commons Attribution 4.0 International License, which permits use, sharing, adaptation, distribution and reproduction in any medium or format, as long as you give appropriate credit to the original author(s) and the source, provide a link to the Creative Commons licence, and indicate if changes were made. The images or other third party material in this article are included in the article's Creative Commons licence unless indicated otherwise in a credit line to the material. If material is not included in the article's Creative Commons licence and your intended use is not permitted by statutory regulation or exceeds the permitted use, you will need to obtain permission directly from the copyright holder. To view a copy of this licence, visit http://creativecommons.org/licenses/by/4.0/. The Creative Commons Public Domain Dedication waiver (http://creativeco mmons.org/publicdomain/zero/1.0/) applies to the data made available in this article, unless otherwise stated in a credit line to the data. 
The American Association of Clinical Endocrinology (AACE) did not recommend general screening for thyroid function in women preparing for pregnancy (or the application of ART) or those who were already pregnant [2]. On the other hand, the guidelines released by the American Thyroid Association (ATA) and the American Society for Reproductive Medicine (ASRM) both recommended screening for TSH in infertile women [3, 4], as did the expert consensus released by the Chinese Medical Association (CMA) [5]. However, the prevalence of thyroid disease in infertile women has not been clearly established; for example, the reported prevalence of subclinical hypothyroidism ranges from 2.3 to $16.7 \%$ in infertile women. In addition, it has been well recognized that serum TSH levels are affected by various factors such as age, gender, iodine intake, and most importantly circadian rhythms. When the blood samples are collected on the early morning (before 9:00), TSH levels are significantly higher than that of the later morning from the same patients $[6,7]$. Although well-designed studies have claimed that TSH reached the nocturnal peak around 2:00 to 4:00, and met the lowest level between 19:00 and 20:00, patients in our Department of Reproductive Medicine usually have the blood samples collected from 7:00 on the morning to 12:00 at noon, during which period the TSH levels are supposed to decline with time regardless of the pulse release every 2-4 h. As expected, when one euthyroid women is sampled early in the morning, the TSH levels may exceed the upper limit of the reference range, which helps the clinician to make the diagnosis of $\mathrm{SCH}$.

To understand the thyroid status of infertile women in our region, and what factors may impact on the assessment of thyroid function, this study retrospectively analyzed the serum TSH, FT3 and FT4 levels based on age and sampling time of infertile women who received ART counseling in the Department of Reproductive Medicine.

\section{Methods}

This was a retrospective study, which initially included the women who came to the Department of Reproductive Medicine of the Third Affiliated Hospital of Zhengzhou University for ART counseling from September 2018 to December 2019. Those with any of the following criterion were excluded: (1) the results were obtained from reexamination; (2) the data of sampling time, age, or serum hormones levels such as TSH, FT3, and FT4 were missing; (3) the results were obtained a year long before the application of ART; (4) the results did not show the classic patterns of thyroid diseases; (5) the patients visited the department for second or more treatment cycles.

The subjects were divided into five groups based on their ages: $<25$ years, $26-30$ years, $31-35$ years, $35-40$ years, and $>40$ years; and into five groups based on the sampling time: 7:00-8:00, 8:00-9:00, 9:00-10:00, 10:0011:00, and 11:00-12:00.

All procedures were in accordance with the institutional review board on human experimentation and with the Helsinki Declaration of 1964 and its later amendments. The informed consent was waived by the Institutional Review Board of the Third Affiliated Hospital of Zhengzhou University.

Before venipuncture, the patients were required to stay calm for $30 \mathrm{~min}$ at least. All fasting blood samples were collected from patients on the 2nd-4th morning of menstruation. The nurses were well trained for the venipuncture. Specifically, after careful check of the information, the nurse firstly placed a tourniquet $5-10 \mathrm{~cm}$ above the elbow, and asked the patient to make a fist. If the vein was obviously raised, the nurse performed strict sterilization with routine aseptic technique, and then fixed the lower end of the vein with the left thumb, and meantime held the needle with her thumb and index finger. Next, the nurse made the needle and the skin at an angle of $30^{\circ}-50^{\circ}$, and quickly penetrated the skin from the center of the blood vessel, and puncture the needle at an angle of $15^{\circ}-20^{\circ}$. Finally, the nurse changed the needle body to a parallel angle with the skin, and inserted a little needle along the vein. After collecting enough blood sample, the nurse release the tourniquet and pull out the needle with a sterile cotton coving the puncture point. Samples were centrifuged at $3000 \mathrm{rpm}$ for $10 \mathrm{~min}$ after at least half an hour. Then, the serum on the upper layer was used for analysis. The measurements of TSH, FT3 and FT4, as parts of the baseline of endocrine hormones for first visitors, were conducted by electrochemical luminescence (ECLIA) on Cobas 8000 (Roche Diagnostics, Germany). The provided TSH reference range is $0.27-4.2 \mathrm{mIU} / \mathrm{L}$, the FT3 reference range is $3.1-6.8 \mathrm{pmol} / \mathrm{L}$, and the FT4 reference range is $12.0-22.0 \mathrm{pmol} / \mathrm{L}$. Daily internal quality control and yearly external quality control were carried out by request.

The criteria for overt hyperthyroidism (Ohyper) were: $\mathrm{TSH}<0.27 \mathrm{mIU} / \mathrm{L}, \mathrm{FT} 4>22.0 \mathrm{mIU} / \mathrm{L}$, and/or FT3 $>6.8$ $\mathrm{mIU} / \mathrm{L}$. The criteria for subclinical hyperthyroidism were (Shyper): TSH $<0.27 \mathrm{mIU} / \mathrm{L}, \mathrm{FT} 4$ levels were in the reference ranges. The criteria for overt hypothyroidism (Ohypo) were: TSH $>4.20 \mathrm{mIU} / \mathrm{L}$ and FT4 $<12.0 \mathrm{mIU} / \mathrm{L}$. The criteria for subclinical hypothyroidism (Shypo) were: $\mathrm{TSH}>4.20 \mathrm{mIU} / \mathrm{L}$, and FT4 levels were in the reference ranges.

Continuous data were expressed as the mean \pm standard deviation. One-way ANOVA or Kruskal-Wallis rank sum test was used for comparison among the groups where appropriate. Categorical data were expressed in number (percentages), and the chi-square test or Fisher's 
Table 1 Distribution of thyroid function based on age [N (\%)]

\begin{tabular}{lcccrrr}
\hline Age & $\mathbf{N}$ & Ohyper $^{\mathbf{a}}$ & Ohypo $^{\mathbf{a}}$ & Shyper $^{\mathbf{a}}$ & Shypo $^{\mathbf{b}}$ & Normal $^{\mathbf{b}}$ \\
\hline$\leq 25$ & 455 & $1(0.22 \%)$ & $1(0.22 \%)$ & $2(0.43 \%)$ & $96(21.09 \%)$ & $355(78.02 \%)$ \\
$26-30$ & 1703 & $5(0.29 \%)$ & $13(0.29 \%)$ & $13(0.76 \%)$ & $325(19.08 \%)$ & $1347(79.09 \%)$ \\
$31-35$ & 1224 & $5(0.40 \%)$ & $4(0.40 \%)$ & $2(0.16 \%)$ & $178(14.54 \%)$ & $1035(84.55 \%)$ \\
$36-40$ & 551 & $3(0.54 \%)$ & $3(0.54 \%)$ & $3(0.54 \%)$ & $87(15.78 \%)$ & $455(82.57 \%)$ \\
$>40$ & 193 & $1(0.51 \%)$ & $2(0.51 \%)$ & $1(0.51 \%)$ & $23(11.91 \%)$ & $166(86.01 \%)$ \\
$P$ & & 0.747 & 0.335 & 0.196 & $<0.001$ & $<0.001$ \\
\hline
\end{tabular}

${ }^{a}$ Fisher's exact test

${ }^{\mathrm{b}}$ Chi-square test

Table 2 Distribution of thyroid function based on sampling time [N (\%)]

\begin{tabular}{lcccccr}
\hline Sampling time & $\mathbf{N}$ & Ohyper $^{\mathbf{a}}$ & Ohypo $^{\mathbf{a}}$ & Shyper $^{\mathbf{a}}$ & Shypo $^{\mathbf{b}}$ & Normal $^{\mathbf{b}}$ \\
\hline 07:00-08:00 & 434 & $1(0.23 \%)$ & $4(0.23 \%)$ & $0(0 \%)$ & $124(28.57 \%)$ & $305(70.27 \%)$ \\
08:00-09:00 & 1081 & $4(0.37 \%)$ & $4(0.37 \%)$ & $6(0.55 \%)$ & $243(22.47 \%)$ & $824(76.22 \%)$ \\
09:00-10:00 & 1248 & $2(0.16 \%)$ & $6(0.16 \%)$ & $9(0.72 \%)$ & $195(15.62 \%)$ & $1036(83.01 \%)$ \\
10:00-11:00 & 829 & $4(0.48 \%)$ & $7(0.48 \%)$ & $4(0.48 \%)$ & $90(10.85 \%)$ & $724(87.33 \%)$ \\
11:00-12:00 & 534 & $4(0.74 \%)$ & $2(0.74 \%)$ & $2(0.37 \%)$ & $57(10.67 \%)$ & $469(87.82 \%)$ \\
$P$ & & 0.348 & 0.486 & 0.500 & $<0.001$ & $<0.001$ \\
\hline
\end{tabular}

${ }^{\mathrm{a}}$ Fisher's exact test

${ }^{\mathrm{b}}$ Chi-square test

exact test was used for comparison where appropriate. The statistical software was SPSS 22.0, and $P<0.05$ was considered as a significant difference among the groups. And adjusted $P<0.003$ was considered as a significant difference when performing the post hoc test.

\section{Results}

General characteristics and distribution of thyroid function of the included population

During the study period, 8486 thyroid tests (TSH, FT3, and FT4) were obtained from 6426 infertile women of childbearing age at the time of ART counseling. Finally this study employed 4126 women who met the included criteria, and were divided into subgroups by age and sampling time. The prevalence of SHYPO decreased significantly with age and sampling time $(P<0.001$, respectively), while the proportion of euthyroid women increased significantly $(P<0.001$, respectively). (Tables 1 , 2)

\section{Serum TSH, FT3 and FT4 levels based on age and sampling time}

The serum TSH, FT3 and FT4 levels of 4088 women were analyzed after 38 women with overt thyroid dysfunction (significant abnormalities in serum TSH, FT3, and FT4 levels) were excluded. The results showed that the mean serum TSH, FT3, and FT4 levels decreased significantly with age (Table 3 ). In the context of sampling time, TSH
Table 3 Comparison of TSH, FT3 and FT4 levels in different age groups [mean (SD)]

\begin{tabular}{|c|c|c|c|c|}
\hline Age & $\mathbf{N}$ & TSH $(I U / L)^{a}$ & FT4 (pmol/L) ${ }^{a}$ & FT3 (pmol/L) \\
\hline$\leq 25$ & 355 & $2.45(0.88)^{\#}$ & 16.45 (1.95) & $5.03(0.49)^{\#}$ \\
\hline $26-30$ & 1347 & $2.43(0.87)$ & $16.37(1.90)$ & $4.84(0.52)^{\#}$ \\
\hline $31-35$ & 1035 & $2.36(0.86)$ & $16.21(1.83)$ & $4.71(0.50)^{\#}$ \\
\hline $36-40$ & 455 & $2.28(0.83)$ & $16.07(1.85)^{*}$ & $4.66(0.51)^{\#}$ \\
\hline$>40$ & 166 & $2.38(0.89)$ & $15.69(1.79)^{\#}$ & $4.56(0.43)^{\#}$ \\
\hline$P$ & & 0.017 & $<0.001$ & $<0.001$ \\
\hline
\end{tabular}

${ }^{a}$ ANOVA test

${ }^{\mathrm{b}}$ Kruskal-Wallis rank sum test

\# Indicates a significant differences compared with any other groups

*Indicates significant differences compared with first 3 groups

levels from early in the morning were significantly higher $(P<0.001)$, while FT4 and FT3 levels were similar in different groups $(P=0.258,0.300$, respectively) (Table 4$)$

\section{Discussion}

In this study, we included a population of infertile women who first visited to our department. The thyroid hormones were detected and analyzed based on age and sampling time. Finally, we observed a decline of serum TSH levels and prevalence of Shypo along with age and sampling time. 
Table 4 Comparison of TSH, FT3 and FT4 levels in different sampling time groups [mean (SD)]

\begin{tabular}{|c|c|c|c|c|}
\hline Sampling time & $\mathbf{N}$ & TSH $(I U / L)^{a}$ & FT4 (pmol/L) ${ }^{a}$ & FT3 (pmol/L) ${ }^{b}$ \\
\hline 07:00-08:00 & 355 & $2.62(0.88)^{\#}$ & $16.22(2.00)$ & $4.80(0.49)$ \\
\hline 08:00-09:00 & 1347 & $2.50(0.85)^{*}$ & $16.16(1.83)$ & $4.76(0.53)$ \\
\hline 09:00-10:00 & 1035 & $2.40(0.86)^{t}$ & $16.29(1.91)$ & $4.78(0.53)$ \\
\hline 10:00-11:00 & 455 & $2.27(0.86)^{*}$ & $16.26(1.88)$ & $4.77(0.51)$ \\
\hline 11:00-12:00 & 166 & $2.19(0.84)^{*}$ & $16.4(1.80)$ & $4.82(0.49)$ \\
\hline$P$ & & $<0.001$ & 0.258 & 0.300 \\
\hline
\end{tabular}

a ANOVA test

${ }^{\mathrm{b}}$ Kruskal-Wallis rank sum test

\# Indicates a significant differences compared with any other groups

*Indicates significant differences compared with first 3 groups.

Thyroid diseases can interfere with the reproductive outcomes of ART, reduce the likelihood of conception, and adversely affect pregnancy outcomes. Overt thyroid dysfunction can be diagnosed and treated in a timely way due to obvious early symptoms and abnormal serum biomarkers. The FT4 levels of Shypo patients were normal, and treatment was delayed due to the absence of obvious clinical symptoms and signs. Krassas et al. [8] systematically analyzed the relationship between thyroid function and human reproductive health, and claimed that as there were differences in the definitions of Shypo or the included patients, the prevalence of Shypo was obviously different among the studies. However, the prevalence was similar between infertile and ordinary women [9]. Our study showed that the total prevalence of Shypo in 4126 women was $17.18 \%$, which was close to the values reported by Shan et al. (16.7\%) [10] and Abalovich et al. (13.9\%) [11]. Ehrenkranz et al. [12] addressed the alteration of serum TSH levels corresponding to circadian rhythm, age, and gender, and suggested that "in order to avoid incorrectly identifying TSH values as abnormal, the TSH reference range, needed to take into account the subject's age and the time of day when the blood sample was drawn".

Plenty studies provided consistent conclusion that age was an independent factor that influenced serum TSH levels, and suggested to establish age-specific, especially elderly-specific TSH levels in order to correctly access the thyroid state. Both Ehrenkranz et al. [12] and Zhai et al. [13] had established age-specific TSH reference intervals. However, either 10 year-intervals or 20 yearintervals were based on to divide the population into different groups, which might obscure the potential impact of age on serum TSH levels. In this study, we found that the prevalence of SHYPO decreased significantly with increasing age, from $21.09 \%$ among women less than 25 years old to $11.91 \%$ in women older than 40 years old, which was inconsistent with the reports from other countries [14, 15]. The study conducted by Zhai et al. [13] included the younger population (both men and women) aged from 19 years old to 44 years old, and claimed slightly decreased median TSH levels from 2.50 to 2.32 $\mathrm{mIU} / \mathrm{L}$, regardless of significantly increased TSH levels in the old reference population. The discrepancy in terms of TSH levels in the younger population between Zhai et al. [13] and ours may be explained by the gender and age intervals. Moreover, Chen et al. [16] demonstrated similar observation among included healthy female population aged 20-40 years old. Even though, our study reported very slightly decreased TSH levels from young to advanced reproductive age. We believed there were little clinical significance in establishing age-specific TSH reference intervals for younger (in contrast to the elderly) infertile women.

Karmisholt et al. [17] claimed that only when the difference between two TSH results in the same Shypo patient (TSH between 4.2 and $12.0 \mathrm{mU} / \mathrm{L}$ ) is no less than $40 \%$ in the absence of treatment could it truly reflect a change in TSH. Therefore, a single detection of TSH might not reflect thyroid problems in patients. There were other studies reporting that the secretion of TSH had a circadian rhythm, which started to rise in the afternoon and peaking after midnight. Chen et al. [6] demonstrated an obvious circadian rhythm of serum TSH levels in 30 healthy people instead of patients with Alzheimer's disease who suffer from day-time agitation, night-time insomnia and restlessness. However, patients from the Department of Reproductive Medicine were mostly have the blood samples drawn in the morning, during which period, the TSH levels were supposed to decrease with time. In this study, blood samples were collected from 7:00 in the morning to 12:00 at noon from infertile women attending our department for ART consultation. We found that the prevalence of Shypo decreased significantly with sampling time, from $28.57 \%$ among women who have blood drawn early in the morning to $10.67 \%$ later in the morning, with TSH levels decreased from 2.62 to $2.19 \mathrm{mIU} / \mathrm{L}$. Ideally, in order to prove circadian changes in TSH serum concentration, we need to test the same patients in different times of the day. This study, regardless of its relative short time period, observed a decline of TSH levels along with time in the morning. Alternative explanations to the finding of different rates of pathological results in different hours of the day in a cohort study could be random, and it could also be the result of patient with Shypo suffering from insomnia and therefore showing up at the clinic at an earlier hour.

According to the prevalence of Shypo reported by Shan et al. [10] approximately $18 \%$ patients who have their blood samples drawn in the early morning would 
be misdiagnosed as Shypo. The observation of this study confirmed the impact of sampling time on the measurement of serum TSH levels, and suggested that consideration of sampling time was strongly required for either resetting of TSH reference range, or interpretation of TSH levels before treatment.

Furthermore, a study pointed out that the reference intervals of serum TSH, FT3 and FT4 were set based on the entire population due to the limitations of the detection methodology, so a TSH result falling within the reference range does not necessarily indicate normal thyroid function. Therefore, for patients with unexplained infertility or high risks of thyroid disease, it is necessary to monitor TSH levels to understand the real status of thyroid function.

There were some limitations in this study. First, this was a retrospective study including a specific population. Second, thyroid globulin antibody and thyroid peroxidase antibody may affect serum TSH levels but were not retrospectively analyzed. Martin et al. [18] reported that the prevalence of Shypo decreased from $2.4 \%$ in the thyroid disease-free population aged $12-19$ years old to $1.8 \%$ in the thyroid disease-free population aged 30-39 years old, and increased ever since 40 years old when thyroid antibodies were negative and cutoff value of TSH was 4.5 $\mathrm{mIU} / \mathrm{L}$. However, the alteration trend of prevalence of Shypo did not change when thyroid antibodies were not taken into consideration. Finally, other chronic diseases that may affect thyroid function were missing.

Nevertheless, the purpose of this study was to obtain a full understand of the basic status of thyroid function in infertile women. We found that among them, the prevalence of Shypo decreased significantly with age and sampling time, so as serum TSH levels, and that FT3 levels also decreased significantly with age. Establishment of reference intervals of FT4 and FT3 based on age and sampling time was unnecessary.

\section{Conclusions}

Age and sampling time were non-negligible factors that may impact on TSH levels; full consideration of age and sampling time should be taken before initiation of treatment.

\footnotetext{
Abbreviations

ART: assisted reproductive technology; TSH: thyroid-stimulating hormones; FT3: free triiodothyronine; FT4: free serum thyroxine; AACE: American Association of Clinical Endocrinology; ATA: American Thyroid Association; ASRM: the American Society for Reproductive Medicine; CMA: Chinese Medical Association; ECLIA: electrochemical luminescence; Shypo: subclinical hypothyroidism; Shyper: subclinical hyperthyroidism; Ohypo: overt hypothyroidism; Ohyper: overt hyperthyroidis.
}

Acknowledgements

Not applicable.

\section{Authors' contributions}

YZ \& YG: Study idea and design, data collection and analysis, editing of the manuscript. XW \& LJ: Study idea and design and critical review. WW and YG: Protocol development and critical review. YL: Collection and analysis of data. All authors read and approved the final manuscript.

\section{Funding}

This work was supported by Grant [LHGJ20190400] from Joint Construction Project of Henan Medical Science and Technology Research Plan. The funding body did not play a role in the design of the study or in the collection, analysis, and interpretation of data or in writing the manuscript.

\section{Availability of data and material}

The original data are available to all readers upon request. Please contact the first author at yuchao1988@yeah.net for such supporting data.

\section{Declarations}

\section{Ethics approval and consent to participate}

This study was approved by the Institutional Review Board of the Third Affiliated Hospital of Zhengzhou University.

\section{Consent for publication}

Consent to participate is not applicable.

\section{Competing interests}

All authors declare no conflict of interest with regard to this study.

\section{Author details}

${ }^{1}$ Department of Reproductive Medicine, The Third Affiliated Hospital of Zhengzhou University, No. 7 Kangfuqian Street, Erqi, Zhengzhou, Henan, China. ${ }^{2}$ Neonatal Screening Center, The Third Affiliated Hospital of Zhengzhou University, Zhengzhou, Henan, China.

Received: 8 March 2021 Accepted: 17 August 2021

Published online: 28 August 2021

\section{References}

1. Rao M, Zeng Z, Zhou F, Wang H, Liu J, Wang R, Wen Y, Yang Z, Su C, Su $Z$, et al. Effect of levothyroxine supplementation on pregnancy loss and preterm birth in women with subclinical hypothyroidism and thyroid autoimmunity: a systematic review and meta-analysis. Hum Reprod Update. 2019;25(3):344-61.

2. Leslie De Groot MAEK. Management of thyroid dysfunction during pregnancy and postpartum: an endocrine society clinical practice guideline. J Clin Endocrinol Metab. 2012;8(97):2543-65.

3. Alexander EK, Pearce EN, Brent GA, Brown RS, Chen H, Dosiou C, Grobman WA, Laurberg P, Lazarus JH, Mandel SJ, et al: 2017 Guidelines of the American Thyroid Association for the Diagnosis and management of thyroid disease during pregnancy and the postpartum. Thyroid 2017, 27(3):315-389.

4. Practice Committee of the American Society for Reproductive Medicine. Subclinical hypothyroidism in the infertile female population: a guideline. FERTIL STERIL. 2015;104(3):545-53.

5. The Forth Committee of Chinese Society of Reproduction Medicine, Chinese Medical Association. Chinese Society for Reproductive Medicine consensus for subclinical hypothyroidism in the infertile female population. Chin J Reprod Contracep. 2019;39(8):609-21.

6. Chen J, Huang C, Ai M, Kuang L. Circadian rhythm of TSH levels in subjects with Alzheimer's disease (AD). Aging Clin Exp Res. 2013;25(2):153-7.

7. Philippe J, Dibner C. Thyroid circadian timing. J Biol Rhythm. 2015;30(2):76-83

8. Krassas GE, Poppe K, Glinoer D. Thyroid function and human reproductive health. EndocrRev. 2010;31(5):702-55.

9. Poppe K, Unuane D, Haeseleer D, Tournaye M, Schiettecatte H, Haentjens J, Velkeniers P. B: Thyroid function after controlled ovarian hyperstimulation in women with and without the hyperstimulation syndrome. Fertil Steril. 2011;96(1):241-5. 
10. Shan Z, Chen L, Lian X, Liu C, Shi B, Shi L, Tong N, Wang S, Weng J, Zhao J, et al. lodine status and prevalence of thyroid disorders after introduction of mandatory universal salt iodization for 16 years in China: a crosssectional study in 10 cities. Thyroid. 2016;26(8):1125-30.

11. Abalovich M, Mitelberg L, Allami C, Gutierrez S, Alcaraz G, Otero P, Levalle O. Subclinical hypothyroidism and thyroid autoimmunity in women with infertility. Gynecol Endocrinol. 2009;23(5):279-83.

12. Ehrenkranz J, Bach PR, Snow GL, Schneider A, Lee JL, Ilstrup S, Bennett ST, Benvenga S. Circadian and circannual rhythms in thyroid hormones: determining the TSH and free T4 reference intervals based upon time of day, age, and sex. Thyroid 2015;25(8):954-61.

13. Zhai X, Zhang L, Chen L, Lian X, Liu C, Shi B, Shi L, Tong N, Wang S, Weng J, et al. An Age-specific serum thyrotropin reference range for the diagnosis of thyroid diseases in older adults: a cross-sectional survey in China. Thyroid 2018;28:1571-9.

14. Vanderpump MP, Tunbridge WM. Epidemiology and prevention of clinical and subclinical hypothyroidism. Thyroid. 2002;12(10):839-47.

15. Somwaru LL, Rariy CM, Arnold AM, Cappola AR. The Natural history of subclinical hypothyroidism in the elderly: the cardiovascular health study. J Clin Endocrinol Metabolc. 2012;97(6):1962-9.
16. Chen J, Zhou W, Pan F, Cui W, Li M, Hu Y. Age-related change in thyroidstimulating hormone: a cross-sectional study in healthy euthyroid population. Endocr J. 2018;65(11):1075-82

17. Karmisholt J, Andersen S, Laurberg P. Variation in thyroid function tests in patients with stable untreated subclinical hypothyroidism. Thyroid. 2008;18(3):303-8.

18. Surks MI, Hollowell JG. Age-specific distribution of serum thyrotropin and antithyroid antibodies in the US population: implications for the prevalence of subclinical hypothyroidism. J Clin Endocrinol Metab. 2007;92(12):4575-82

\section{Publisher's Note}

Springer Nature remains neutral with regard to jurisdictional claims in published maps and institutional affiliations.
Ready to submit your research? Choose BMC and benefit from:

- fast, convenient online submission

- thorough peer review by experienced researchers in your field

- rapid publication on acceptance

- support for research data, including large and complex data types

- gold Open Access which fosters wider collaboration and increased citations

- maximum visibility for your research: over $100 \mathrm{M}$ website views per year

At BMC, research is always in progress.

Learn more biomedcentral.com/submissions 